\title{
HOW TO GET MANAGEMENT SKILL IN THE COURSE OF INFORMATICS?
}

\author{
Ladislav Burita \\ University of Defence, Brno, Czech Republic
}

CMESTE

JEL Category: 121, M15, 032

\begin{abstract}
The article introduces the content and methods of informatics education respecting a focus on management. Students of the communication and information systems branch are future officers of the Czech Armed Forces. Their main mission will be managing and working with people. This fact and the development of the so-called soft skills in management are taken into consideration in the teaching of informatics-related topics. Gradually, the article deals with individual topics of the course: management, organization and analysis of information sources, knowledge management systems and project management. The use of pedagogical methods is particularly emphasized by independent student work, the development of their creativity and innovativeness. In the literature review, there was not found any similar document with the theme of the paper. In the analyzed articles were discussed the various forms of leadership development and was emphasized the importance of ICT for innovativeness. The management part in the course is focused on management functions, management cycle OODA, and cycle PDCA of processes improving. The organization of the information sources and analysis of the text document is based on the explanation of the information systems development procedure and using Tovek Tools. The part of the course in knowledge management systems and project management is an opportunity for students to work independently in developing their own knowledge system and project planning.
\end{abstract}

Keywords: management, education, informatics, ICT, CIS, university, students, CAF.

\section{INTRODUCTION}

The article informs about the teaching of ICT (information and communication technology) military specialists at the University of Defense (UoD), Faculty of Military Technology; Department of Informatics, Cyber Security, and Robotics. A fundamental change took place in 2014 when moving from a two-level study (Bachelor and

Address of the author:

Ladislav Burita

琵/ladislav.burita@unob.cz
Master) to a continuous five-year engineering study. The UoD changed their study programs on a request from the Ministry of Defense (MoD) and General Staff of the Czech Armed Forces (CAF). The study plans were successfully accredited within the faculty. A new study program was an opportunity to innovate the content of the teaching courses.

This paper introduces the course of the Communication and Information Systems (CIS) Management which is being taught in the fifth year of study. During the course, we try to develop a specific skill in team cooperation, decision-making 
based on obtaining the necessary information, leadership, autonomy, creativity, innovativeness, etc. The mission of future officers, CIS specialists, after they graduate from the university, will be management, leadership, and cooperation with people. Few of the students can imagine it; they usually assume that somewhere in the CIS workplace they will perform expert assignments of communications, informatics, or security.

The basic prerequisite for the management of CIS people is, of course, as well as in other fields of expertise, a high-quality CIS expert base. It is complicated to prepare university students for their future role as commander. Students, although passing a course of management in general subjects, are certainly not adequately prepared.

That is the reason why the course CIS Management was included in the program of specialization to further develop the students in the field of management, considering their professional orientation. We build on the functions of the management cycle from which the parts of the subject matter are developed, such as organizing and analyzing information resources to support the decision-making process and working with knowledge.

\section{THE LITERATURE REVIEW}

The literature review about management in information technology or ICT and on soft skill development was based on articles indexed at Web of Knowledge and Scopus. The articles analyzed various contexts in the search topic, but no match was made directly to the article's focus. In relation to teaching, ICT is presented in particular with its implementation in teaching courses, integration into other subjects, and the focus of individual ICT disciplines on teachers and students. Regarding soft skill development were available papers with explaining the term, its importance, classifications, and ways to its development. The next topic in the literature was analyzed soft skills in connection to project management.

In an article (Drent \& Meelissen, 2008), the factors that stimulate or limit the innovative use of ICT by teacher educators in the Netherlands were mentioned. Creative use of ICT is defined as the use of ICT applications that support the educational objectives based on the needs of the current knowledge society. Explorative path analysis and case studies were used to study the potential influencing factors. Results show that several factors at the teacher level influence the implementation of innovative ICT-use in education. Teachers who are so-called 'personal entrepreneurs' are particularly important for the integration of ICT in teacher education.

The paper (Webb, 2005) presents an analysis of how affordances of ICT-rich environments identified from a recent review of the research literature can support students in learning science in schools within a proposed framework for pedagogical practice in science education. Furthermore, other pedagogical and curriculum innovations in science education are examined to see how they may be supported by ICT. It identified support learning through four main effects: promoting cognitive acceleration; enabling a wider range of experience so that students can relate science to their own and other real-world experiences; increasing students' selfmanagement; and facilitating data collection and presentation.

The nature of soft skill is explained in the paper (Levasseur, 2013), includes self-awareness, communication, collaboration, and leadership. In the information systems branch are mentioned: interaction with users and clients, work cooperatively in a project team, understand the business environment, be self-directed and proactive, and be able to analyze IS solutions to business problems. In project management discipline, contain oral and written communication, a strong work ethic, teamwork, initiative, and well interpersonal behavior. The environments for developing soft skills in practice include self-study, training, mentoring, and couching.

The article (Vinichenko, Ridho, Kirillov, Makuchkin, \& Melnichuk, 2017) discusses the development of leadership skills in the talent management system. The methods of research were questionnaire surveys, content analysis, and mathematical data processing. The study of the respondents' opinion on the nature of leadership development in the talent management system allowed establishing some parity between soft skills and hard skills. Almost half of the respondents consider the development of soft 
skills to be important for increasing the competitiveness of the organization.

Participating students apply in the education principles of learning to their own practice as they learn to incorporate theories and reflect on their impact on their projects, within their own contexts. They report this to be an effective approach as it reinforces their learning and highlights practical outcomes. The success of this approach is attributed to integrating principles from a wide range of interdependent disciplines including action learning, leadership, project management, reflective practice, sense-making, stakeholder engagement, problem-based learning and knowledge management. Reflecting on the impacts of soft skills in their own projects enhances learning outcomes and develops their professional capabilities. (Shelley, 2015)

\section{MANAGEMENT}

The first part of the course education is the topic of management. Students need to be told that this is a very broad concept. Managing means having subordinates under one's leadership to control, manage, and regulate. It is about how to lead, manage, manage things; control, induce others to adopt domination, agree to decision by motivation, action, and manipulation to achieve the desired goal. Significantly, we understand management as a designation of a profession, a group of workers, a field of study, or a scientific discipline.

Management is a systematic and coordinated process leading to a predetermined goal. It is supposed to bring some results with the best possible use of the human, material and financial resources that the organization (and hence the manager) has at its disposal. The aim is above all to evaluate all inputs, and the resulting benefit depends on managerial and professional assumptions as well as the engagement of managers responsible for organizational management. The management process is composed of the functions: Planning, Organizing, Commanding, and Controlling.

In the military environment is mostly mentioned the OODA (Observe-Orient-Decide-Act) management cycle (Mulder). Each phase of the cycle can be supported by appropriate information processing technologies. The most important phase is orientation, which affects both the creation of the right alternatives for decision and the method of observation and that functions are supported by ICT, used in the course.

Getting practice skills in management can only be handled in practice. The student must be put in a role where management functions can be applied to subordinates or colleagues. This can be difficult during the study. A selected student performs the function of group commanders, but to command of classmates is quite difficult. Management can also be tested in the role of team leader in the classroom if teams are set up to solve a common task. Students at an internship in military troops can obtain the best experience in management before getting into practice.

The PDCA (Plan-Do-Check-Act) (Mulder) processes are applied as an iterative, four-stage approach for continually improving processes and for resolving problems (see Fig. 1). The students verify the PDCA cycle mainly for seminar, credit or final work:

- Plan: Identify and analyze the problem or opportunity, develop hypotheses about what the issues may be, and decide which one to test.

- Do: Test the potential solution, ideally on a small scale, and measure the results.

- Check/Study: Study the result, measure effectiveness, and decide whether the hypothesis is supported or not.

- Act: If the solution was successful, implement it.

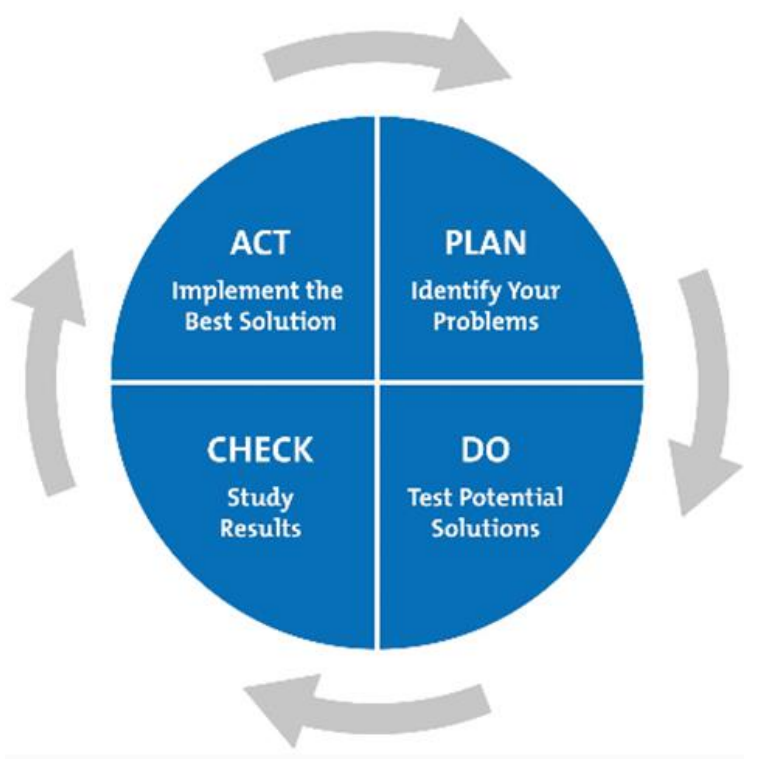

Fig. 1. PDCA cycle, Source: (Mind Tools, 2019) 


\section{ORGANIZATION OF} INFORMATION SOURCES

The course includes parts of the information system (IS) and its structure:

- People in different roles (users, administrators, creators, managers).

- Data, information, and knowledge.

- ICT technical resources - (computers, communication systems, data storages ...).

- Methods, procedures and ICT tools (languages, development environments ...).

- Management of running and organizing work (guidelines, security, and ergonomics).

In the military environment, the ISs are divided into administrative and war fields. The fielding IS are labeled as Operational Tactical Command and Control Systems; in NATO they are known as C2IS (Command and Control IS) and their aim is to improve the overview on the battlefield (situational awareness), rationalize work, facilitate decision-making, link reconnaissance-command and weapon systems and achieve greater combat effectiveness.

The center of interest for future military specialists is the Army Staff System of the CAF, which is operated in a closed army domain and includes:

- Information Portal (news, free positions, phonebook, security questionnaire ...).

- Access to other IS MoD (financial, personnel, logistics ...).

- Other information sources (process model of the MoD, military crew, headquarters, Lessons Learned, central services, foreign military missions ...).

- E-mail to all military personnel, connected to the network.

From the point of view of CIS management, it is important to get acquainted with the process of creating the IS and its life cycle (LC) in the army environment, which includes 6 phases, and within them are created 25 documents in total.

\section{Phase 1 "Design Concept"}

1. Project intent.

2. Security plan.

3. Specifications.

Phase 2 "Development"

4. Tender documentation.

5. Contract.
6. Introductory study.

7. CIS development plan.

8. Security documentation

9. Project documentation.

Phase 3 "Implementation"

10. Regulation for the testing process.

11. Protocol about the test run.

12. Regulation to initiate operational use.

13. Operational security documentation.

14. Operational security guidelines for classified NATO CIS.

15. Operating user documentation.

16. Protocol at the end of the project.

17. Protocol on the take-over of CIS for operational use.

Phase 4 "Operation and Use"

18. CIS operation plan.

19. Maintenance plan.

20. Records of disturbances and emergencies.

21. Subsystem management records.

Phase 5 "Support and Change"

22. Migration proposal.

23. Draft modification.

Phase 6 "Decommissioning"

24. Evaluation of CIS.

25. Protocol on the disqualification of CIS.

Students as a team prepare documents of the selected LC stage in the seminar work. They have all documentation on the IS LC. In addition, the Guidelines on the competencies of individual roles in the IS LC, are assigned to the teamwork.

\section{ANALYSIS OF THE TEXT DOCUMENTS}

The right decision depends on the situation analysis, including the analysis of information sources. Documentation systems, such as SW Tovek Tool (TT) (Tovek, 2019), the professional tool for analyzing the information sources and text mining, are designed for this purpose and are used in the course.

TT consists of five modules:

1. Index Manager (IM) for indexing data sources.

2. Tovek Agent (TA) for search in indexed data.

3. InfoRating (IR) for context analysis among the retrieved documents.

4. Query Editor (QE) to create complex queries.

5. Harvester $(\mathrm{HA})$ for detail content analysis. 
Information sources for analysis can be text documents, websites, databases, and e-mail. The information resources are first processed by the $I M$, which creates an index file. The search is then performed in the index file using the TA or QE module. The results of a simple search create a first result of what concepts (keywords) are contained in documents and can prepare their simple segmentation. It then enables the development of a broad analysis of search documents using more complex queries or the performance of contextual or content analysis using IR and $\mathrm{HA}$.

This part of the course develops mainly autonomy and the ability to find solutions. The assignment is usually general; its purpose is to analyze a specified set of documents. In particular, students will design information analysis goals and strategies and then step by step to achieve the objectives of the analysis using all TT modules. Their progress and results are documented in the protocol; the results are presented in their defense at the seminar.

\section{KNOWLEDGE SYSTEMS}

In the theoretical part of the course, students are lectured the basic principles of working with knowledge, their classification, acquisition, and processing. Students learn that knowledge is:

- Explicit, which can be described verbally, expressed through a scheme, an image, or defined in another formal way. It is easily communicable.

- Hidden (Tacit), which includes experience, skills, and intuition. They are often tied to their individual wearers who may not even know about it. It is not directly communicable.

Human knowledge is divided into procedural (how to do something), declarative (describing what we know), heuristic (problem-solving based on previous experience), structural (describes mental models and organization), inaccurate and uncertain (often inaccessible, incomplete, random, associated with probability), ontological (devoted to a domain) and others.

To develop practical applications, it is necessary to gain human knowledge (from experts or other sources), to understand it correctly, to record it in a formal representation, to verify it in a practical intelligent system and to develop it further. It is not easy to capture the knowledge engineer either in direct dialogue or by observing experts - direct and indirect techniques.

Direct:

- Discussion, questionnaire.

- Expert observation at work.

- Recording and query analysis

Indirect:

- Imagination - knowledge assumptions (knowledge assumptions).

- Expert recognizes old patterns in new issues far before others.

- Different forms of recording (text, tables, hierarchies, networks, flow charts).

- Grouping of knowledge and group processing (clustering, arrangement, and hierarchy).

Knowledge management is a process, social and technological system for preserving, developing, sharing and spreading knowledge. It is an approach to finding, understanding and using knowledge in an organization to create value, improving organizational performance, and achieving its goals. Knowledge management, rather than technology, focuses on methods and procedures.

In practical education, students create their own knowledge system, based on methodology, and verified in the departmental research. They use the ATOM system (aion, 2019), an application accessible on the Internet; its processing is fully outsourced by Company AION CS, Zlín. ATOM is a non-programming web database SW that does not require specialized knowledge; anyone can easily construct a knowledge system on it. The system contains the powerful full-text search engine and integrates information about objects in the knowledge base.

The complete ATOM solution includes three layers (environments):

1. ATOM Studio: Ontology Designer, user administration, batch data in/output module.

2. Data Editor: Includes data into the database via the ontology.

3. User Portal: Approach to the knowledge system.

The methodology of the knowledge management system (KMS) development includes some steps. 
At first, it creates the ontology of the problem domain in the Ontology designer. Students suggest their own KMS and analyze a problem domain. The ontology design consists of two tasks:

- the schema of the classes and associations, defined in the SW Visual Understanding Environment (VUE) (see Fig. 2) and
- classes elaboration in the table form (see Tab. 1).

Then the ontology is prepared for implementation into the Ontology designer (see Fig. 3). The students' work example is "Using the softwaredefined radio (SDR) in the Cipher CAD environment". The form for including data about SDR is in Fig. 4; an example for SDR IZ255.

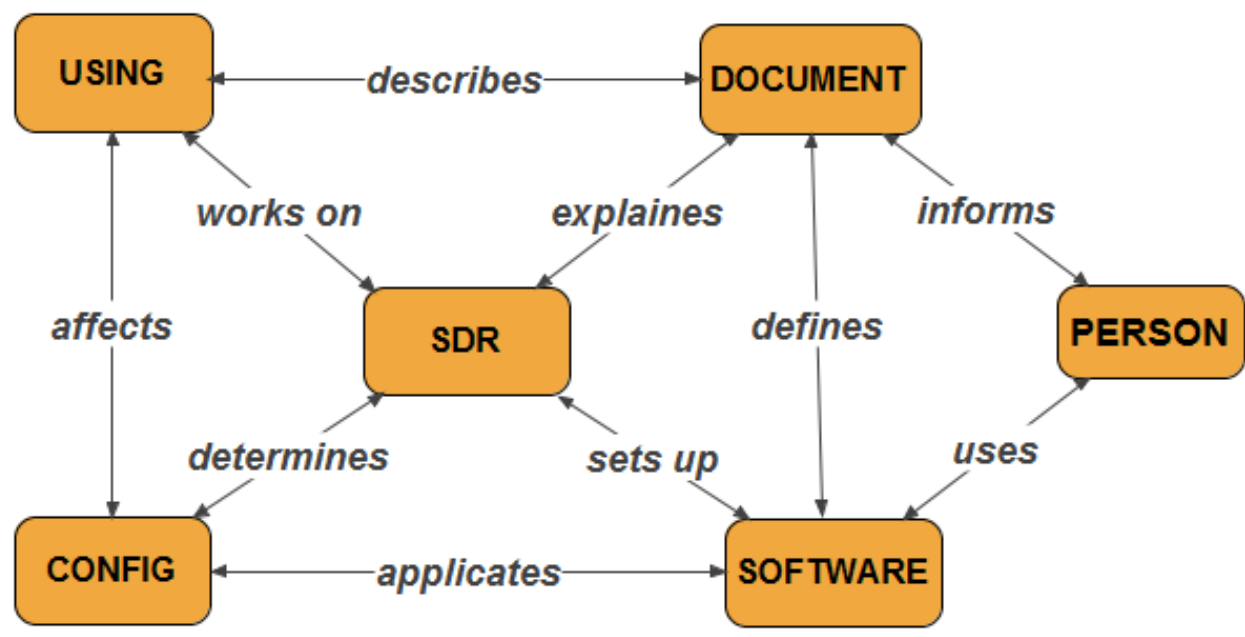

Fig. 2. Ontology design - a schema of classes and associations; Source: own (student work)

Tab. 1. Ontology design - classes and their characteristics; Source: own (student work)

\begin{tabular}{|l|l||c|c|c|c|c|c|}
\hline Attribute & Data type & USING & CONFIG & SDR & PERSON & SOFTWARE & DOCUMENT \\
\hline \hline price & number & & & & & $\mathbf{X}$ & \\
\hline sensitivity & number & & & $\mathbf{X}$ & & & \\
\hline format & text & & & & & & $\mathbf{X}$ \\
\hline freq-band & text & & & $\mathbf{X}$ & & & \\
\hline category & text & $\mathbf{X}$ & & & & & \\
\hline name & text & & & & $\mathbf{X}$ & & \\
\hline license & text & & & & & $\mathbf{X}$ & \\
\hline options & text & & $\mathbf{X}$ & & & & \\
\hline par-others & text & & & $\mathbf{X}$ & & & \\
\hline num-pages & number & & & & & & $\mathbf{X}$ \\
\hline requirement & text & & & & & $\mathbf{X}$ & \\
\hline professional & boolean & $\mathbf{X}$ & & & & & \\
\hline source & URI & & & & & & $\mathbf{X}$ \\
\hline met-of-use & text & & $\mathbf{X}$ & & & & \\
\hline
\end{tabular}




\begin{tabular}{|c|c|c|c|}
\hline Class (6 items) & $\triangle$ Association (10 items) & $\Delta$ Text (9 items) & Variant (5 items) \\
\hline 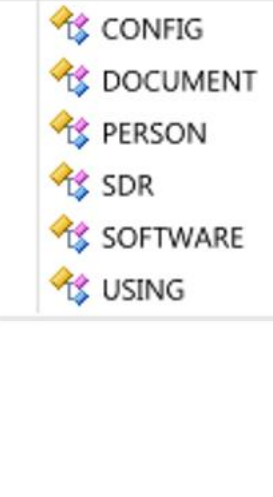 & $\begin{array}{l}\Leftrightarrow \text { affects } \\
\Leftrightarrow \text { applicates } \\
\Leftrightarrow \text { defines } \\
\Leftrightarrow \text { describes } \\
\Leftrightarrow \text { determines } \\
\Leftrightarrow \text { explains } \\
\Leftrightarrow \text { informs } \\
\Leftrightarrow \text { sets up } \\
\Leftrightarrow \text { uses } \\
\Leftrightarrow \text { works on }\end{array}$ & $\begin{array}{l}\mathrm{A}^{\mathrm{a}} \text { category } \\
\mathrm{A}^{\mathrm{a}} \text { format } \\
\mathrm{A}^{\mathrm{a}} \text { freq-band } \\
\mathrm{A}^{\mathrm{a}} \text { license } \\
\mathrm{A}^{\mathrm{a}} \text { met-of-use } \\
\mathrm{A}^{\mathrm{a}} \text { name } \\
\mathrm{A}^{\mathrm{a}} \text { options } \\
\mathrm{A}^{\mathrm{a}} \text { par-others } \\
\mathrm{A}^{\mathrm{a}} \text { requirement }\end{array}$ & $\begin{array}{l}\text { num-pages } \\
\text { price } \\
\text { professional } \\
\text { sensitivity } \\
\text { source }\end{array}$ \\
\hline
\end{tabular}

Fig. 3. Ontology implementation in Ontology designer; Source: own (student work)

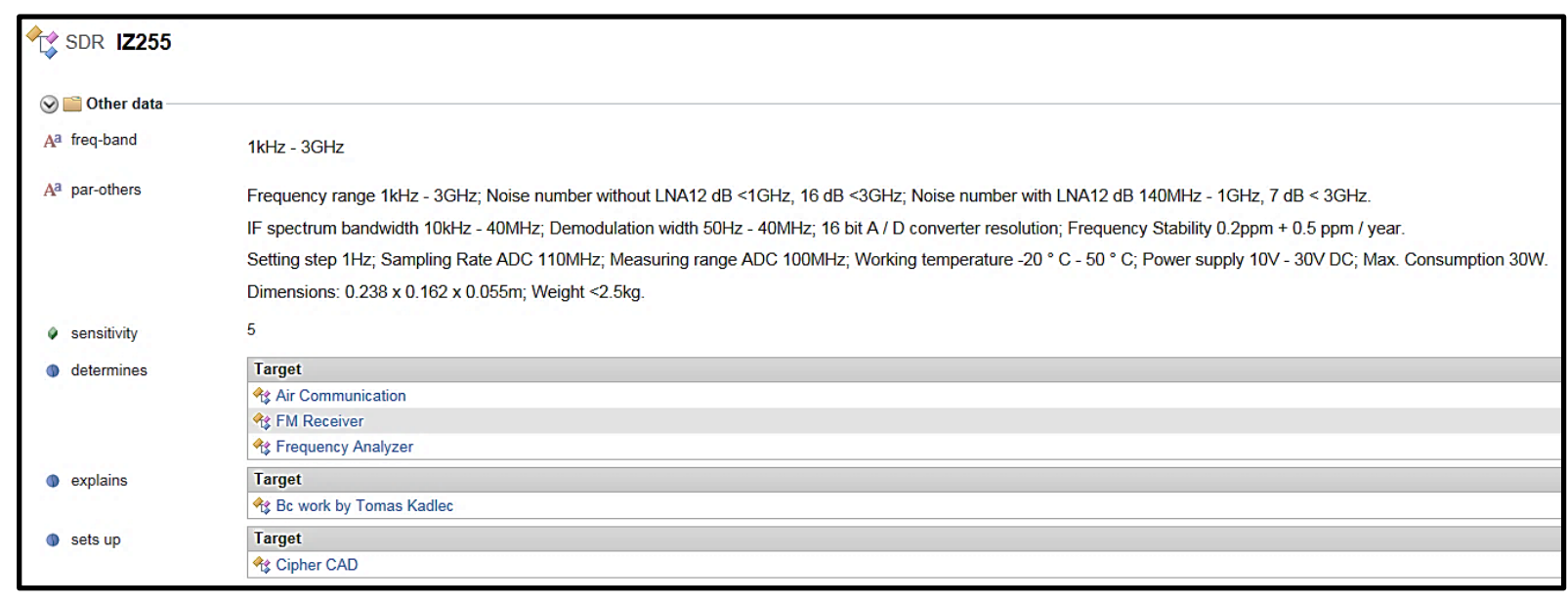

Fig. 4. KMS development - a form of the class SDR; Source: own (student work)

\section{PROJECT MANAGEMENT}

Students are acquainted with the basics of project management (PM) and prepare the project as a seminar work. The characteristics, the conditions of success and phases of the project are important in the theoretic part of the education.

Project characteristics:

- Time Boundary (Temporary, Start, End).

- Clearly defined goals (including the requirement for the quality of results).

- A working process aimed at achieving goals (achievement of change).

- Uniqueness, non-cyclic, breadth, complexity.

- Limited resources, uncertainty, risk.

- Unified efforts of experts of various branches (synergy of activities).

Project success conditions:
- The setting goals and priorities; all activities must be planned.

- Sufficient provision of resources (personnel, finance, technology, time).

- Strong support and interest of project owners.

- Involvement in the project of the involved and affected groups.

- Quality organizational framework.

- Manager's responsibility and authority.

- Designation of risks and measures for their elimination.

- Reliable team communication.

Project phases:

1. Preparatory, initialization.

2. Planning, design.

3. Implementation.

4. Evaluation, termination.

The project requirements are specified in the preparatory phase: 
- They are unambiguous and relate to some of the project's parts.

- It is possible to trace and test them (the content of fulfillment).

- Create a good starting point for project analysis.

- They have the necessary details, are consistent (not in conflict).

- Are written in user language (understandable to users).

The planning of the project primarily means setting its goals and defining strategies to achieve them; creating a decomposition of project activities and developing plans (timing, cost, allocation of resources, a matrix of responsibilities) and optimizing them.

In addition, techniques and tools for PM and communication are chosen, restrictions and risks are identified, and a proposal to eliminate them is adopted.

Management of the project concerns the implementation of plans, the coordination of solution subjects, team communication, and conflict resolution. The analysis, correction, and evaluation of the project (time, costs, and resources) must be carried out while ensuring the quality of the project; the management of the opposition proceedings and the change management meetings, all with reliable technical and administrative support.

Students need to emphasize that project designing is a complex and risky activity that is often unsuccessful (up to $70 \%$ ) in which managers have an irreplaceable role. If possible, organize practical lessons in teams. In it, students learn how to control MS Project and plan their own diploma work and the result is given in the form of a seminar paper.

\section{CONCLUSION}

The article deals with a partial theme of teaching and preparing the students of UoD, future military specialists in the field of CIS. It introduces the subject of CIS Management, whose mission is in the background of teaching informatics, developing knowledge and skills in management and working with people. The special ambition of the subject is to develop students' soft skills in such a way that their practical involvement in CAF functions is realized with minimal problems. Further research of the department, in relation to the objectives of the CIS Management course, will be focused on verifying how we manage to meet in the subject's defined goals.

The contribution of the article, in the field of expertise, is the specification of the course of informatics and management, the teaching of the students at the UoD, future CAF officers. The taught disciplines suitably support management and decision-making skills, in accordance with the management cycle steps. In the field of pedagogy, there are described in each discipline the methods of how to develop the practical skills of the manager by developing a suitable soft-skill for leadership.

\section{WORKS CITED}

aion. (2019, 02 10). Software AToM. Retrieved from aion: Available at: www.aion.cz

Drent, M., \& Meelissen, M. (2008). Which factors obstruct or stimulate teacher educators to use ICT innovatively? Computers \& education, 51(1), 187-199.

Levasseur, R. (2013). People Skills: Developing Soft Skills-A Change Management Perspective. Interfaces, 43(6), 566-571. doi:10.1287/inte.2013.0703

Mind Tools. (2019, 12 15). Plan-Do.Check-Act. Retrieved from Mind tools: https://www.mindtools.com/pages/article/newPPM_89.htm

Mulder, P. (n.d.). OODA Loop. Retrieved 12 05, 2019, from toolshero: Available at https://www.toolshero.com/decision-making/ooda-loop/

Shelley, A. (2015). Project management and leadership education facilitated as projects. International journal of managing projects in business, 8(3), 478-490.

Tovek. (2019, 12 15). Tovek Tools. Retrieved from Tovek: https://www.tovek.cz/cs/tovek-tools.html 
Vinichenko, M., Ridho, T. K., Kirillov, A., Makuchkin, S., \& Melnichuk, A. (2017). Development of Skills Management In The System Management of Talents. Modern journal of language teaching methods, 7(9), 50-57. Retrieved from https://pdfs.semanticscholar.org/a655/e9588c98cf2111ccb683fea8e78bd7eaceaf.pdf

VUE. (n.d.). Software VUE - Visual Understanding Environment. Retrieved 10 02, 2019, from VUE: http://vue.tufts.edu/

Webb, M. (2005). Affordances of ICT in science learning: implications for an integrated pedagogy. International journal of science education, 27(6), 705-735.

Received for publication: $\quad 12.12 .2019$

Revision received: $\quad 23.12 .2019$

Accepted for publication: $\quad 10.01 .2020$

\section{How to cite this article?}

Style - APA Sixth Edition:

Burita, L. (2020, January 15). How to get management skill in the course of informatics? (Z. Cekerevac, Ed.) MEST Journal, 8(1), 48-56. doi:10.12709/mest.08.08.01.06

Style - Chicago Sixteenth Edition:

Burita, Ladislav. 2020. "How to get management skill in the course of informatics?" Edited by Zoran Cekerevac. MEST Journal (MESTE) 8 (1): 48-56. doi:10.12709/mest.08.08.01.06.

Style - GOST Name Sort:

Burita Ladislav How to get management skill in the course of informatics? [Journal] // MEST Journal / ed. Cekerevac Zoran. - Belgrade - Toronto : MESTE, January 15, 2020. - 1 : Vol. 8. - pp. 48-56.

Style - Harvard Anglia:

Burita, L., 2020. How to get management skill in the course of informatics?. MEST Journal, 15 January, 8(1), pp. 48-56.

Style - ISO 690 Numerical Reference:

How to get management skill in the course of informatics? Burita, Ladislav. [ed.] Zoran Cekerevac. 1, Belgrade - Toronto : MESTE, January 15, 2020, MEST Journal, Vol. 8, pp. 48-56. 